Volume 3 • Nomor 2 • Februari 2020

Pege (Hal.) : $62-67$

(C) Universitas Pamulang

JL.Surya Kencana No.1 Pamulang, Tangerang Selatan - Banten

Telp. (021) 7412566, Fax (021) 7412491

website. :

Email : jurnalmarketing.unpam@gmail.com

\title{
Pengaruh Promosi Dan Penetapan Harga Terhadap Keputusan Pembelian Produk Cendo
}

\author{
Arif Siaha Widodo', Surti Wardani ${ }^{2}$ \\ Universitas Pmulang \\ Email: dosen01725@unpam.ac.id
}

\begin{abstract}
Abstrak. Penelitian ini bertujuan untuk mengetahui apakah terdapat pengaruh promosi terhadap keputusan pembelian produk cendo produksi PT Penta Valent Jakarta, untuk mengetahui apakah terdapat pengaruh penetapan harga terhadap "keputusan pembelian" produk cendo produksi "PT Penta Valent Jakarta" dan untuk mengetahui apakah terdapat pengaruh antara "promosi dan penetapan harga" secara simultan terhadap "keputusan pembeliaan produk cendo produksi "PT Penta Valent Jakarta". "Metode analisis" digunakan uji regresi linier berganda, Uji t dan Uji F. Populasi dalam penelitian yaitu semua konsumen yang menggunakan produk cendo produksi PT Penta Valent Jakarta, dengan sampel "100 responden". Hasil menunjukkan promosi berpengaruh positif terhadap "keputusan pembelian" produk cendo produksi PT Penta Valent Jakarta dengan nilai koefisien yaitu "sebesar "0,519 dengan nilai t hitung $>$ t tabel atau 5,884 $>1,660$. Penetapan Harga berpengaruh positif terhadap keputusan pembelian dengan nilai koefisien yang di dapatkan "sebesar 0,327" dengan nilai t hitung > t tabel atau 8,007 >1,660. Promosi dan penetapan harga secara simultan berpengaruh positif dan signifikan terhadap keputusan pembelian produk cendo produksi PT Penta Valent Jakarta, dengan persamaan $Y=7,210+0,519 \times 1+0,327 \times 2$ dan nilai $F$ hitung $>F$ tabel yaitu $60,369>$ 3,090 http://openjournal.unpam.ac.id/index.php/JPK/article/view/4496
\end{abstract}

\section{Kata kunci : Promosi; Penetapan Harga; Keputusan Pembelian}

Abstract. This study aims to determine the effect of promotion on the purchase decision of PT Penta Valent Jakarta products, to find out the effect of price setting on the "purchase decision" of cendo product PT Penta Valent Jakarta" and to determine the silmultaneous effect of "promotion and price determination on the purcahse decision of cendo product "PT Penta Valent Jakarta". The "analysis method" is used multiple linear regression test, $t$ test and $F$ test. The population are all the consumers who use cendo product PT Penta Valent Jakarta and the sample size are "100 respondents". The results show a positive effect of promotion on the "purchase decision" of cendo PT Penta Valent Jakarta with a coefficient value of "equal to" 0.519 and $t$ value $>t$ table or 5.884> 1,660. Pricing has a positive effect on purchasing decisions with a coefficient value obtained "of 0.327 " and $t$ valuet $>t$ table or $8.007>1,660$. Promotion and price simultaneously have a positive and significant effect on 
purchasing decisions for cendo product PT Penta Valent Jakarta, with the equation $Y=7.210$ $+0.519 X 1+0.327 X 2$ and $F$ value $>F$ table that is $60,369>3,090$.

Keywords: Promotion; Pricing; Purchase Decisions

\section{A. PENDAHULUAN}

PT Penta Valent didirikan pada bulan September 1968 di Jakarta. Penta Valent adalah distributor produk farmasi, kesehatan atau kosmetik, dan konsumen di Indonesia dengan 34 cabang menyediakan layanan di seluruh negeri. Farmasi dipasok ke lebih dari 14.988 apotik, 4.536 toko obat dan 1.325 rumah sakit dan produk kesehatan atau kosmetik. Bisnis produk farmasi, kesehatan, dan lain sebagainya tidak ada matinya, hal ini mungkin membuat bisnis ini tetap bertahan dan menjadi pilihan bisnis favorit bagi para pelaku usaha berskala besar maupun kecil.

Tabel 1 Data Penjualan Produk Cendo PT Penta Valent dari tahun 2014-2018

\begin{tabular}{|l|l|l|l|l|l|}
\hline Tahun & Target & Pencapaian & $\%$ & Harga & Jumlah \\
\hline 2014 & 32.000 .000 & 25.725 .000 & $80 \%$ & $R p 27.000$ & $R p 694.575 .000 .000$ \\
\hline 2015 & 42.000 .000 & 30.825 .000 & $73 \%$ & $R p 32.000$ & $R p 986.400 .000 .000$ \\
\hline 2016 & 52.000 .000 & 41.450 .000 & $79 \%$ & $R p 34.000$ & $R p 1.409 .300 .000 .000$ \\
\hline 2017 & 62.000 .000 & 45.150 .000 & $73 \%$ & $R p 36.000$ & $R p 1.625 .120 .000 .000$ \\
\hline 2018 & 72.000 .000 & 55.150 .000 & $76 \%$ & $R p 40.000$ & $R p 2.206 .000 .000 .000$ \\
\hline
\end{tabular}

Sumber Data : PT Penta Valent

Dari data diatas menunjukkan bahwa produk cendo dari tahun 2014 sampai dengan tahun 2018 mengalami penaikan yang fluktuatif atau tidak stabil,dengan target yang dibebankan sedangkan penjualan produk cendo dari tahun 2015 mencapai 25.725 .000 produknya setara $80 \%$ dan pada tahun 2018 sebesar 55.150 .000 produknya setara $76 \%$ Terjadi penurunan pada penjualan produk cendo secara fluktuatif.

Tujuan Penelitian adalah untuk menjawab : Apakah promosi dan penetapan harga berpengaruh positif dan signifikan terhadap keputusan pembelian baik secara parsial/sendiri ataupun simultan/ bersama -sama?

\section{B. KAJIAN LITERATUR}

\section{Promosi}

Menurut Sukirno dan Poerwanto (2014:194) "promosi merupakan suatu ungkapan dalam arti luas tentang kegiatan-kegiatan yang secara efektif dilakukan oleh perusahaan untuk mendorong konsumen membeli produk atau jasa yang ditawarkan".

\section{Harga :}

Tjiptono (2014:198) berpendapat bahwa harga adalah sejumlah uang (dalam satuan moneter) dan aspek yang lain (non moneter) yang mengundang utilitas atau manfaat tertentu yang dibutuhkan untuk mendapatkan suatu jasa. Utilitas merupakan atribut atau faktor yang berpotensi memuaskan keinginan tertentu. 


\section{Keputusan Pembelian :}

Buchari Alma (2013:96) berpendapat bahwa "Keputusan pembelian adalah suatu keputusan konsumen yang dipengaruhi oleh ekonomi keuangan, teknologi, politik, budaya, produk, harga, lokasi, promosi, physical evidence, people, dan process sehingga membentuk suatu sikap pada konsumen untuk mengolah segala informasi dan mengambil kesimpulan berupa respon yang muncul produk apa yang akan dibeli".

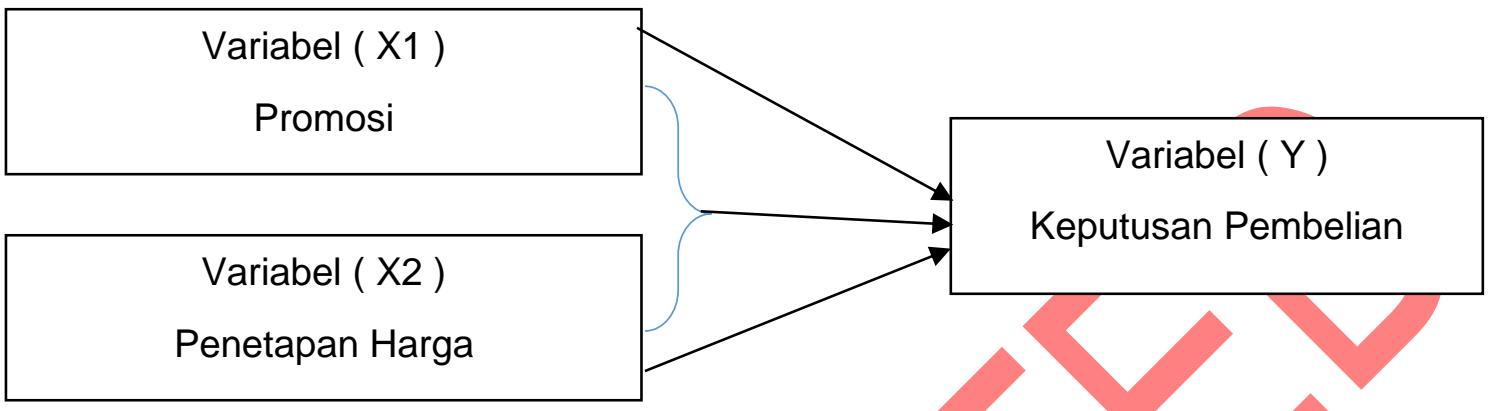

\section{METODOLOGI PENELITIAN}

Populasi dalam penelitian ini adalah semua konsumen yang menggunakan produk cendo produksi PT Penta Valent Jakarta. Dengan sampel berjumlah 100 orang. Dalam menganalisis data menggunakan uji linier berganda untuk mengetahui pengaruh, baik pengaruh secara parsial/ sendiri maupun pengaruh secara simultan/bersama - sama.

\section{HASIL DAN PEMBAHASAN}

Regresi Linier berganda

Tabel 2. Hasil Uji Regresi Linier Berganda

\begin{tabular}{|c|c|c|c|c|c|}
\hline \multicolumn{6}{|c|}{ Coefficlenta: } \\
\hline \multirow[t]{2}{*}{ iㅔ } & \multicolumn{2}{|c|}{ Jnsiandardized Coufficienis } & \multirow{2}{*}{\begin{tabular}{|c} 
Standiardond \\
Coufficients \\
Buta
\end{tabular}} & \multirow[t]{2}{*}{$\mathrm{T}$} & \multirow[t]{2}{*}{ Sig. } \\
\hline & E & Sud Error & & & \\
\hline (Constan) & 7.210 & 3.054 & & 2361 & .020 \\
\hline masi $X 1$ & 519 & 몋 & 463 & 5.164 & 000 \\
\hline$x_{2}$ & .327 & 075 & 355 & 4.327 & 000 \\
\hline
\end{tabular}

spendant Varbak: Y Keputusan Pembelian

Sumber : Data Diolah

Dari hasil hitung regresi pada tabel diatas, maka diperoleh persamaan regresinya sebagai berikut : yaitu $\mathrm{Y}=7,210+0,519\left(\mathrm{X}_{1}\right)+0,327\left(\mathrm{X}_{2}\right)$. Maka kesimpulan dari persamaan tersebut adalah : 


\section{Kompetilif}

ISSN NO. (PRINT) 2598-0823, (ONLINE) 2598-2893

1) "Apabila nilai konstanta 7,210 maka dapat diartikan apabila variabel $X_{1}$ dan $X_{2}$ tidak ada maka terdapat keputusan pembelian 7,210".

2) "Dengan nilai 0,519 maka diartikan jika nilai konstanta tetap dan tidak ada perubahan pada variabel $\mathrm{X}_{2}$, dan apabila terdapat perubahan 1 unit pada variabel $\mathrm{X}_{1}$ maka akan mengakibatkan terjadinya perubahan pada Y sebesar 0,519 point".

3) "Dengan Nilai 0,327 maka diartikan jika nilai konstanta tetap dan tidak ada perubahan pada variabel $\mathrm{X}_{1}$, dan apabila terdapat perubahan 1 unit pada variabel $\mathrm{X}_{2}$ maka akan mengakibatkan terjadinya perubahan pada Y sebesar 0,327 point"

\section{Uji Hipotesis t}

Tabel 3 Hasil Uji t Promosi terhadap Keputusan Pembelian

\section{Coefflciente"}

\begin{tabular}{|c|c|c|c|c|c|}
\hline \multirow[t]{2}{*}{ 테 } & \multicolumn{2}{|c|}{$\begin{array}{r}\text { Unstandardized } \\
\text { Coefficients }\end{array}$} & \multirow{2}{*}{\begin{tabular}{|c|} 
iandardized \\
Coefficienis \\
Beta \\
\end{tabular}} & \multirow[t]{2}{*}{$\mathbf{t}$} & \multirow[t]{2}{*}{ Sig. } \\
\hline & $\mathbb{B}$ & di. Enror & & & \\
\hline istant] & 7210 & 3.054 & & 2.281 & .020 \\
\hline "rombesi & .519 & .008 & -463 & 6.ES4 & .000 \\
\hline
\end{tabular}

Ependent Variabla: $\mathrm{Y}$

Bupher: Data Primer fahun 2010, dowah dengan SPSS vers 20

Dari tabel diatas diperoleh nilai $t_{\text {hitung }}>t_{\text {tabel }}(5,884>1.660)$, dengan nilai signifikansi sebesar $0,000<0,05$. terdapat pengaruh yang positif dan signifikan secara parsial antara promosi terhadap keputusan pembelian pada PT Penta Valent Jakarta

Tabel 4 Hasil Uji t Penetapan Harga terhadap Keputusan Pembelian Coefflelents's

\begin{tabular}{|c|c|c|c|c|c|}
\hline \multirow[t]{2}{*}{ 베 } & \multicolumn{2}{|c|}{ Unstandartized Coeffieients } & \multirow{2}{*}{\begin{tabular}{|c} 
Sunderdized \\
Dotficients
\end{tabular}} & \multirow[t]{2}{*}{ 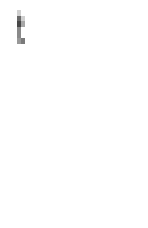 } & \multirow[t]{2}{*}{ Sg. } \\
\hline & [ & Sit. Ertar & & & \\
\hline \multirow[t]{2}{*}{ istint] } & 16.400 & 2785 & & 6.570 & 000 \\
\hline & .578 & 072 & B29 & 8.007 & 000 \\
\hline
\end{tabular}

sumber : Data Fimer thum 2010, dobh denpan SPSS ver/ 20 
Dari tabel diatas diperoleh nilai $t_{\text {hitung }}>t_{\text {tabel }}(8.007>1.660)$, dengan nilai signifikansi sebesar $0,000<0,05$. terdapat pengaruh yang positif dan signifikan secara parsial antara penetapan harga terhadap keputusan pembelian pada PT Penta Valent Jakarta.

\section{Uji Hipotesis $f$}

Tabel 5 Hasil Uji f Simultan

\begin{tabular}{|c|c|c|c|c|c|}
\hline \multicolumn{6}{|c|}{ ANOYA' } \\
\hline 테 & ini of Suluares & dif & and Square & $F$ & Sigi: \\
\hline "Hsion & 1204.502 & 2 & 602.251 & 60.369 & $.000^{7}$ \\
\hline dual & 967.686 & 97 & 9.976 & & \\
\hline I & 2172.190 & 99 & & & \\
\hline
\end{tabular}

ependen Variabla: $Y$ : Kepulisan Fembelian

\section{b. Predicars: (Constani), Pendapan Harga X2, Promasi X1}

\section{Sumber : Data Primer tahun 2019, (0ovin)}

tabel diatas, dapat di jelaskan bahwa nilai $F$ hitung lebih besar dari $F$ tabel atau $(60.369>$ 3090), dengan nilai signifikansi $0,000<0,05$. Maka $\mathrm{H}_{0}$ ditolak dan $\mathrm{H}_{1}$ diterima. Dengan demikian dapat di simpulkan terdapat pengaruh positif dan signifikansi secara simultan antara promosi dan penetapan harga terhadap keputusan pembelian pada PT Penta Valent Jakarta.

\section{E. Kesimpulan}

1. "Variabel Promosi berpengaruh positif dan signifikan terhadap keputusan pembelian dimana hasil uji hipotesis diperoleh $t$ hitung $>t$ tabel atau $(5,884>1,660)$ dengan signifikasi $0,000<0,05 "$.

2. "Variabel Penetapan Harga berpengaruh positif dan signifikan terhadap keputusan pembelian dimana hasil uji hipotesis diperoleh thitung $>t$ tabel atau $(8,007>1,660)$ dengan signifikasi $0,000<0,05$,

3. "Dari hasil penelitian, dapat di simpulkan bahwa variabel promosi dan variabel penetapan harga berpengaruh positif terhadap keputusan pembelian dengan persamaan regresi $Y=7,210+0,519 X_{1}+0,327 X_{2}$. dan nilai $F$ hitung $>F$ tabel yaitu $(60.369$ $>3090$ ), dengan nilai signifikansi $0,000<0,05$ maka semakin tinggi promosi dan penetapan harga maka akan semakin meningkatkan keputusan pembelian".

\section{DAFTAR PUSTAKA}

Ali, Hasan,"Marketing dan Kasus-Kasus Pilihan", CAPS ( Center For Academic Publishing Service ), Yogyakarta, 2013. 
Alma, Buchari," Manajemen Pemasaran dan Pemasaran Jasa " , CV Alfabeta, Bandung, 2012.

Alma, Buchari," Manajemen Pemasaran dan Pemasaran Jasa" , CV Alfabeta, Bandung, 2013.

Kotler, P dan Keller, K," Manajemen pemasaran “ , Edisi 12, Erlangga, Jakarta, 2012.

Kotler, Philip, dan Amstrong ," Prinsip-prinsip Pemasaran" , Edisi 13 Jilid 1, Erlangga, Jakarta, 2012

Kotler, Philip. \& Gary Armstrong," Principle Of Marketing" , Pearson Prentice Hall, New Jersey 2014.

Kotler, Philip and Keller , Kevin Lane, “ Manajemen Pemasaran” , Jilid 1, Edisi 13, Erlangga, Jakarta, 2013.

Laksana , Fajar, 2013, “ Manajemen Pemasaran Pendekatan Praktis " , Penerbit Graham Ilmu, Yogyakarta.

Lesmana, R. (2017). Pengaruh Citra Perusahaan Terhadap Keputusan Pembelian Konsumen Pt. Garuda Indonesia Tbk.(Persero). JIMF (Jurnal IImiah Manajemen Forkamma), 1(1).

Lupiyoadi, Rambat," Manajemen Pemasaran Jasa Teori dan Praktik" ", Salemba Empat, Jakarta, 2014.

Rangkuti, Freddy," Customer Care Excellence" , Gramedia, Jakarta, 2017.

Sugiyono , " Metode Penelitian Kuantitatif, Kualitatif dan R\&D ”, CV Alfabeta, Bandung, 2012

Sugiyono , "" Metode Penelitian Kuantitatif, Kualitatif, dan R\&D ", CV Alfabeta, Bandung, 2016

Tjiptono, Fandy," Strategi Pemasaran" , Edisi 4,Andi, Yogyakarta, 2015 
Pamulang, 27 November 2022

No. : 044/JPK/XI/2022

Lampiran : -

Perihal : Penarikan Artikel Secara Permanen

Kepada Yth:

Bapak Arif Siaha Widodo

Ibu Surti Wardani

Universitas Pamulang

Dengan hormat,

Sehubungan dengan permintaan penarikan artikel jurnal secara permanen dari Bapak Arif Siaha Widodo dan Ibu Surti Wardani dikarenakan data pada artikel tersebut tidak sesuai dengan fakta dari perusahaan maka dengan ini kami sampaikan bahwa artikel pada Jurnal Kompetitif Volume 3 No 2, Februari 2020 dengan judul : "Pengaruh Promosi Dan Harga Terhadap Keputusan Pembelian Produk Cendo" sudah kami hapus secara permanen.

Demikian kami disampaikan, atas perhatiannya kami ucapkan terimakasih.

Hormat kami,

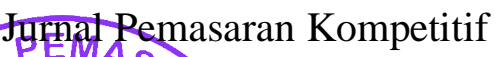

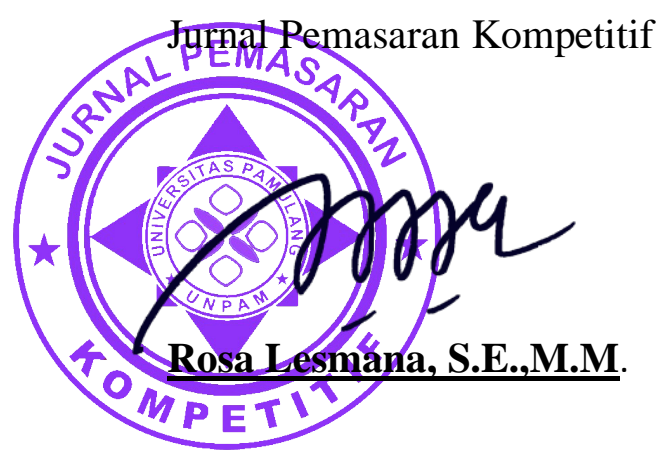

